\title{
Electrical signature of the October 2013 very severe cyclonic storm Phailin
}

\author{
Adarsh Dube ${ }^{1}$, Ajeet K. Maurya ${ }^{2}$ and Rajesh Singh ${ }^{1, *}$ \\ ${ }^{1}$ Dr K. S. Krishnan Geomagnetic Research Laboratory, Indian Institute of Geomagnetism, Allahabad 221 505, India \\ ${ }^{2}$ Department of Physics, Doon University, Dehradun 248 001, India
}

In this study we examine first of its kind from Indian sub-continent which concentrates the electrical signatures of lightning discharges associated with a very severe cyclonic storm (VSCS). Phailin cyclone during 8-14 October 2013 has been selected for the study. We have primarily used ground-based GLD360 network lightning data to understand the distribution, polarity and radiated peak current of lightning discharge associated with the inner core $(\sim 100 \mathrm{~km}$ radius $)$ of Phailin. In the initial development stage of Phailin as a deep depression on 8-9 October, there were very few lightning discharged $(>50)$ in the inner core, but when Phailin developed into a VSCS on 10 October, $\sim 2300$ lightning discharges were recorded in inner core. There was near-even distribution of positive cloud to ground and negative cloud to ground discharges in the core, and with strong opposite peak currents of $\pm 150 \mathrm{kA}$ prior to the cyclone landfall. The observations show that monitoring of lightning discharges in eye of the cyclone is helpful in tracking its intensity changes and hence can serve as early warning systems.

Keywords: Electrical signature, lightning discharges, peak current, tropical cyclone.

TROPICAL cyclones are a potential source of turbulence, wind shear, storm surges, gusts and gale, thunderstorms, heavy rainfall, lightning discharges, etc. ${ }^{1}$. The intensity of tropical cyclones is estimated based on satellite imagery of clouds and cloud parameters ${ }^{2}$. A cyclone typically consists of a precipitation-free eye surrounded by an eyewall, with deep convection and spiral rain bands outside the eyewall ${ }^{3}$. According to their characteristics and locations, spiral rain bands can be classified into inner and outer rain bands ${ }^{3,4}$. Inner rain bands are usually invisible to space-based satellite imagery, but are evident on groundbased radar reflectivity. Outer spiral rain bands are defined as those rain bands that occur outside the inner core. They generally have larger horizontal scales than the inner rain bands. Although rain bands are distinct features of a tropical cyclone, they may interact with the eyewall thus modulating its structure and intensity ${ }^{5,6}$.

In general, inner rain bands in the cyclone are always active immediately outside the eyewall up to a radius of

\footnotetext{
*For correspondence. (e-mail: rajeshsing03@gmail.com)
}

about $\sim 60 \mathrm{~km}$. Although the outer spiral rain bands dominate outside $\sim 60 \mathrm{~km}$ radius, their activity shows a quasiperiodic nature ${ }^{6-8}$. Previous studies have shown that the convection in the inner core of a tropical cyclone is intense and can be studied for tropical cyclone intensity forecasting and cyclone track changes ${ }^{9,10}$. Zhang et al. ${ }^{10,11}$ reported details of different features of a tropical cyclone and related lightning activity study for the intensity change forecasting. These studies showed marked changes in lightning outbreak prior to storm intensification. Studies have also reported that eyewall lightning could be a potential predictor to changes of storm track and storm intensity ${ }^{10-12}$. They also observed that an increase in $+\mathrm{CG}$ (cloud-to-ground) lightning might be considered as a prediction for storm weakening.

To analyse and track lightning discharge activity associated with large tropical cyclones has become more interesting over the years due to the latest ground- and space-based remote sensing techniques. Usage of lightning discharge records over the last 30 years for mapping the tropical cyclone intensity and its track forecasting is a boon to society, considering the associated destructiveness ${ }^{13}$. In such scenario, ground-based lightning networks for the study of tropical cyclone evolution, structure and energetics become important. Kaplan et $a l .{ }^{14}$ showed that lightning input influences the identification of rapidly intensifying and rapidly weakening cyclone cases as much as many other parameters that are currently utilized in an operational rapid intensification index. Lightning data from space based Optical Transient Detector (OTD) and Lightning Imaging Sensor (LIS) on-board the Tropical Rainfall Measuring Mission (TRMM) satellite have been used to study the relationship between lightning activity and cyclone intensity ${ }^{15,16}$. However, as the OTD and LIS do not provide a continuous coverage of lightning within a cyclone, they are by design not the most suitable tools to examine the relationship between lightning activity and change in intensity of a cyclone. There are errors of false detections due to background illuminations from bright cloud tops, high-energy particles, non-lightning optical signals such as solar glint reflections from the oceans and sensor noise ${ }^{15,17}$.

One of the important reasons for choosing and reliability of GLD360 dataset over OTD/LIS is that because of the short viewing times, the detection efficiency of 

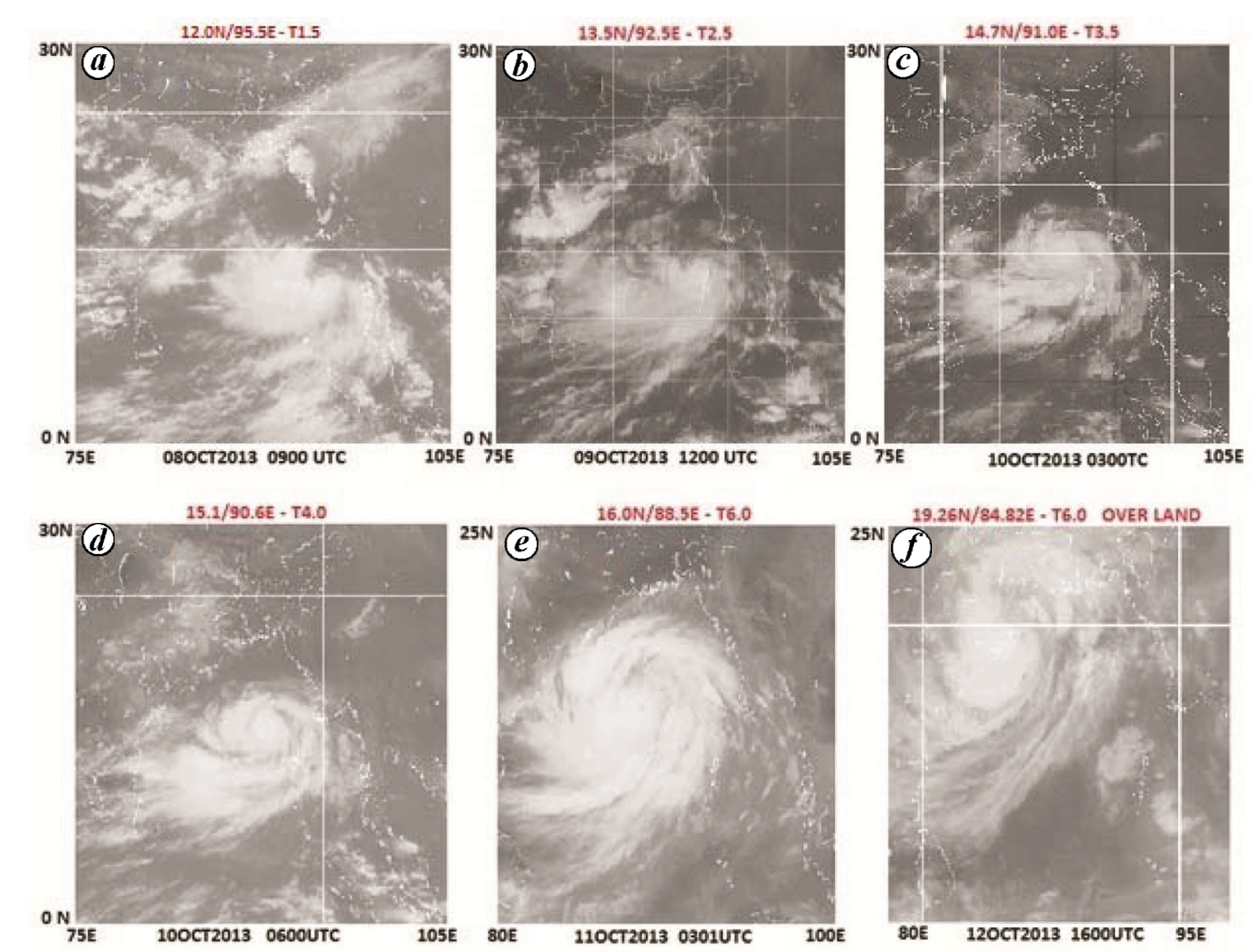

Figure $1 \boldsymbol{a}-\boldsymbol{f}$. Infrared imagery of cloud cover growth and decay obtained from Kalpana-1 satellite with intensity $(T)$ of VSCS Phailin during 8-12 October 2013.

OTD/LIS is less compared to the ground-based lightning detection networks like global lightning dataset $(\text { GLD360 })^{18}$. The ground-based networks geo-locate lightning continuously on global and regional scales more efficiently and provide additional information on the polarity and energy radiated by the lightning discharges. The development of ground-based long-range lightning detection networks allows for the study of a larger set of cyclones and hurricanes systems over the open ocean and basins ${ }^{19-21}$. Abarca et al. ${ }^{19}$ studied tropical cyclones of the Atlantic Basin and found that lightning activity in the inner core has the potential to distinguish between intensifying and non-intensifying cyclones during weaker stages. Price et al. ${ }^{20}$ studied lightning activity in the Mediterranean region to find possible causes for flashfloods. Demaria et $a l .{ }^{21}$ studied the cyclonic storms of East-Pacific and Atlantic Basin.

Previous studies mainly from the North Atlantic and eastern North Pacific Oceans, which used ground-based lightning detection network data, focused on understanding the nature of lightning discharge and electrical energy radiated $^{9-13,22}$. However, study of distribution of lightning discharges, \pm discharge polarity and energy radiated from a tropical cyclone of the Indian region is lacking. Therefore, to fill this gap, we studied the nature and characteristics of lightning activity associated with a tropical cyclone from the Bay of Bengal in the Indian sub- continent. To the best of our knowledge, there are no reports from the Indian sub-continent providing insight on the energy budget of thunderstorms/lightning discharges associated with a tropical cyclone. For this purpose, we have selected a very severe cyclonic storm (VSCS) Phailin of category 4 (Saffir-Simpson scale) $)^{23,24}$, which occurred in the Bay of Bengal during 8-14 October 2013. VSCS Phailin formed in the Bay of Bengal on 8 October 2013, and after its landfall on 12 October at Gopalpur, Odisha (geo. lat $19.2^{\circ} \mathrm{N}$; geo. long $84.9^{\circ} \mathrm{E}$ ) on east coast, the cyclone dissipated during 13-14 October 2013 over the northeastern part of India. Figures 1 and 2 show the pattern of lightning discharges in the Phailin cycloneaffected regions. We concentrated on understanding the lightning distribution, \pm discharge polarity and energy radiated in eye of the cyclone along its line of track (Figure 2). The study shows that monitoring cyclone eye lightning discharges is useful for cyclone forecasting. The lightning distribution during the entire active period starting with the initial stages of cyclone formation and then moving towards intensification and decay after landfall is discussed in this study.

\section{Data}

The VSCS Phailin best track evolution and details of its intensity information during 8-14 October 2013 has been 

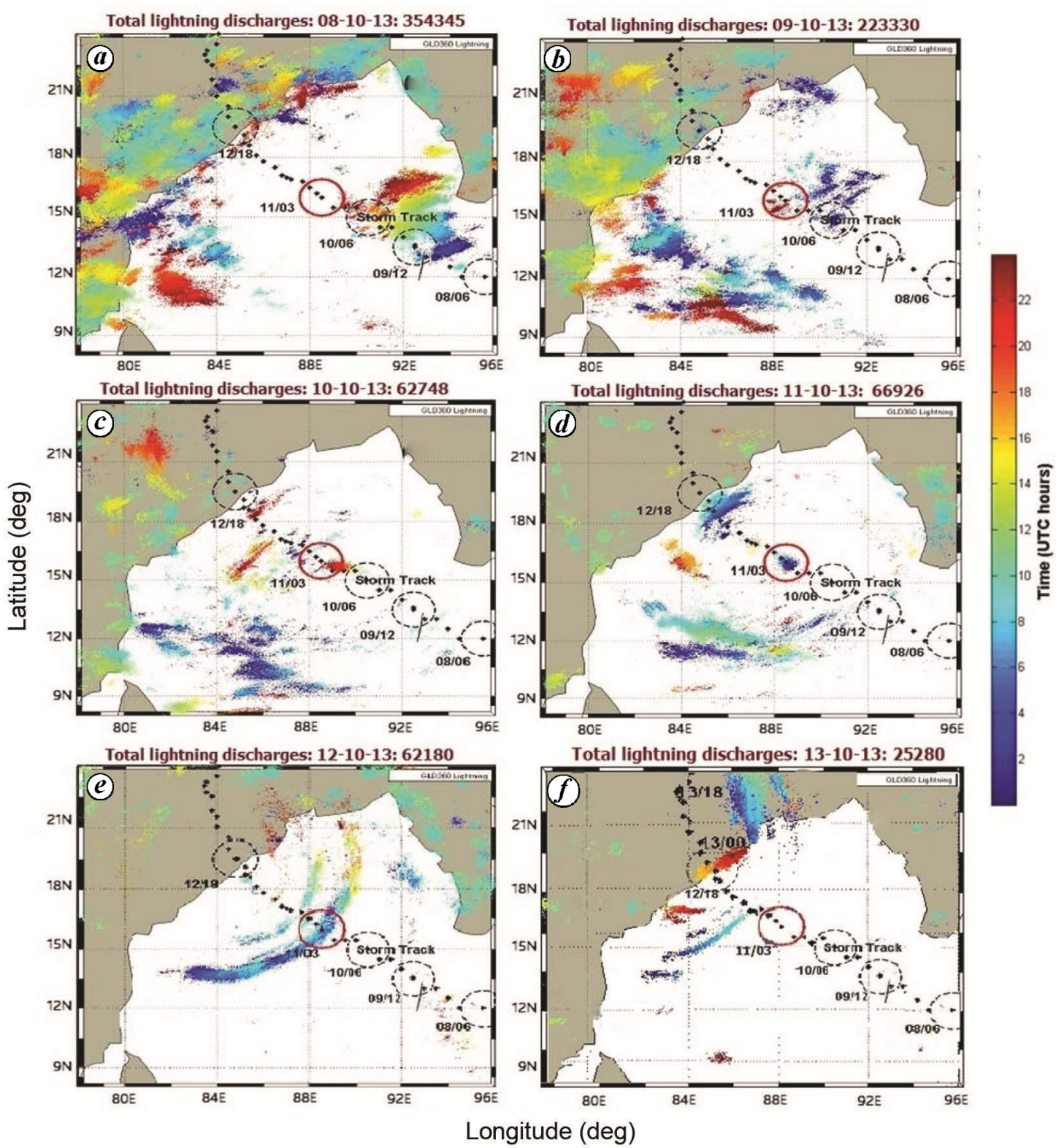

Figure $2 \boldsymbol{a}-\boldsymbol{f}$. GLD360 lightning distribution shown in terms of time colour code during 8-13 October 2013 in the region affected by tropical cyclone 'Phailin'. The cyclone movement line of track is also depicted.

obtained from Cyclone Warning Services (http://www. imd.gov.in/pages/services cyclone.php) of India Metrological Department (IMD) ${ }^{25}$. To understand the associated cloud characteristics during VSCS Phailin, we have used Kalpana-1 satellite infrared (IR) imagery data obtained from Meteorological and Oceanographic Satellite Data Archival Centre, Space Applications Centre, Indian Space Research Organisation (ISRO) (https://mosdac.gov.in/). The main aim of this study is to understand the spatial and temporal distribution, discharge polarity and energy radiated by lightning discharge associated with VSCS Phailin. For this, we have used GLD360 network lightning data provided by Vaisala Inc (https://www.vaisala.com $)^{18}$.

\section{Observations and discussion}

Figure 1 shows the IR imagery as observed from Kalpana-1 satellite of the deep cloud cover associated with Phailin. The cyclone with maximum intensity T6.0 (on Dvorak's intensity scale $^{2}$ ) originated from a remnant tropical depression with T1.5 over the Bay of Bengal on 8 October 2013 (Figure $1 a$ ). According to the IMD report ${ }^{25}$, the first warning for a depression was issued on 8 October at 03:00 h UTC. Subsequently, falling in the line of a track, the depression developed into a cyclonic storm with T2.5 on 9 October at 12:00 h UTC (Figure $1 b$ ). It further developed into a severe cyclone with T3.5 at 03:00 h UTC and into a very severe cyclone with T4.0 at 06:00 h UTC 
on 10 October 2013 (Figure $1 c$ ). The cyclone continued moving towards the Indian coastline, i.e. northwestwards from its origin in Bay of Bengal (Figure $1 d$ ). It stayed alongside the east coast of India on 11 October, reaching a maximum intensity of T6.0 at 03:00 h UTC (Figure $1 e$ ) and came in the category of VSCS. Upon landfall on 12 October around the location of $19.2^{\circ} \mathrm{N}$ and $84.9^{\circ} \mathrm{E}$ on the east coast (Figure $1 f$ ), the intensity of Phailin was still T6.0. In subsequent days of 13-14 October, the cyclone weakened and dissipated over the eastern part of India.

Figure $2 a-f$ shows lightning activity during $24 \mathrm{~h}$ of the day associated with the deep convective cloud cover of VSCS Phailin during 8-12 October 2013 as presented in Figure 1. Figure $2 a-f$ also incorporates cyclone movement line of track according to records of IMD. In Figure 2, the eye of the cyclone is depicted with black circles of $100 \mathrm{~km}$ radius on the line of track. The eye of the cyclone was clearly visible on 11 October and is distinguished with a red circle marked in Figure $1 d$. In order to study the spatial and temporal distribution of lightning discharges associated with Phailin, lightning data from GLD360 Network were used. The ground-based network of GLD360 uses the very low-frequency (VLF) electromagnetic energy emitted during lightning discharges to estimate the time, location, discharge polarity and radiated peak current of lightning discharges ${ }^{18}$.

Lightning during the initial stages of the cyclone on 8 October (Figure $2 a$ ) was mostly concentrated over mainland India and with lesser lightning activity in the Bay of Bengal. When Phailin intensified to category T2.5 on 9 October (Figure $2 b$ ), we observed an increase in lightning activity in the Bay of Bengal area. It is important to note that when the cyclone attained the intensity of T4.0 on 10 October, lightning activity started to follow the spiral cloud band of Phailin in the Bay of Bengal (Figure $2 c$ ). On 11 October the cyclone was fully developed with intensity T6.0 and with a clear visible eye. The eye of Phailin on 11 October with lightning activity concentrated in it is marked in Figure $2 d$ with a red circle. All the lightning activity on 11 October was also found to be concentrated along the spiral rain band of the cyclone. The recent enveloped eyewall lightning (EEL) signatures reported by Vagasky $^{26}$ are seen here too, marked with a red circle. Cyclone landfall on the east coast at Gopalpur happened on 12 October and still with the maximum intensity of T6.0. On 13 October, the cyclone moved further over the mainland and dissipated subsequently in a couple of days.

Since cyclone movement is along a line of track, and it is on this track line that the 'eye' which is the signature of a VSCS appears, next we present lightning discharge details in the eye of the cyclone. In forecasting cyclone intensity, lightning activity is being considered in other countries, and lightning activity in eye of cyclone is much helpful ${ }^{26}$. Figure 3 presents the distribution of lightning discharges along with the polarity of $\pm \mathrm{CG}$ (cloud-to-ground) discharges and radiated peak current concentrated in the eye of the cyclone (100 km radius) along the cyclone track line during 8-14 October 2013. The left vertical panel in Figure 3 shows the histograms of total number of lightning discharges along with distribution of $+\mathrm{CG}$ and $-\mathrm{CG}$ lightning discharges in the eye of the cyclone. The right vertical panel in Figure 3 shows the radiated peak current $\mathrm{kA}$ by $\pm \mathrm{CG}$ lightnings in the eye of the cyclone. All the details presented in Figure 3 are estimated based on three hourly averaging of lightning data from GLD360 network at $100 \mathrm{~km}$ radius from the cyclone centre on the track. We found that the inner core eye lightning activity on 8 October was minimal and maximum peak current observed was $140 \mathrm{kA}$. On 9 October in the eye of the cyclone the discharges were again minimal and the maximum peak current of lightning discharges was $78 \mathrm{kA}$. The important intense days during 10-12 October when Phailin changed its intensity from T3.5 to T6.0 were marked as mature stage with a redlined box in Figure 3. Also, 10 October recorded the maximum number of lightnings, i.e. 2333 counts in the eye of the cyclone, which is maximum during all seven days of the cyclone presented in Figure 3. Clearly three bursts of lightning discharge marked as growth 1-3 were seen on 10 October between 13 and $21 \mathrm{UT}$, and this was the period when Phailin changed its intensity from $\sim$ T4.0 to T6.0. On 10 October, $45.73 \%$ of the lightning activity in the eye was of $+\mathrm{CG}$ polarity and the rest $-\mathrm{CG}$ polarity. The maximum peak current in $+\mathrm{CG}$ discharges was $105 \mathrm{kA}$, whereas the maximum peak current in -CG discharges was $108 \mathrm{kA}$.

This shows that there is some sort of electrical balance in terms of discharges \pm polarity, and also in terms of \pm peak current of discharges when the storm intensified towards T4.0 and higher on 10 October. We presume that this polarization and approximate charge balance, may have helped the system to further grow and intensify. It was on this day according to the IMD alert that the cyclone intensified from a severe cyclonic storm (SCS) to a $\mathrm{VSCS}^{25}$. Earlier studies by Zhang et al. ${ }^{10,11}$ reported that a large number of lightning discharges occur during the intensification stage of the storm. The second peak in lightning activity in the eye was seen at 06:00 h UT on 11 October. The observations reported here follow the studies of Abarca et al. ${ }^{19}$, Cecil and Zipser ${ }^{15}$ and Zhang et $a l .{ }^{10,11}$, that lightning outbreaks from the inner core are large in number during the intensifying stage of the cyclone. On 12 October the number of lightnings decreased considerably in the $100 \mathrm{~km}$ radius eye on the line of the track of the cyclone. Also, important to note is that there was a decrease in peak current of discharges, the maximum peak current in $+\mathrm{CG}$ lightning was $76 \mathrm{kA}$ and in $-\mathrm{CG}$ lightning it was $116 \mathrm{kA}$. And $57.78 \%$ of the lightning had $+\mathrm{CG}$ polarity. Also, $+\mathrm{CG}$ lightning was more common in the storm weakening stages, whereas -CG lightning was abundant during the strengthening 


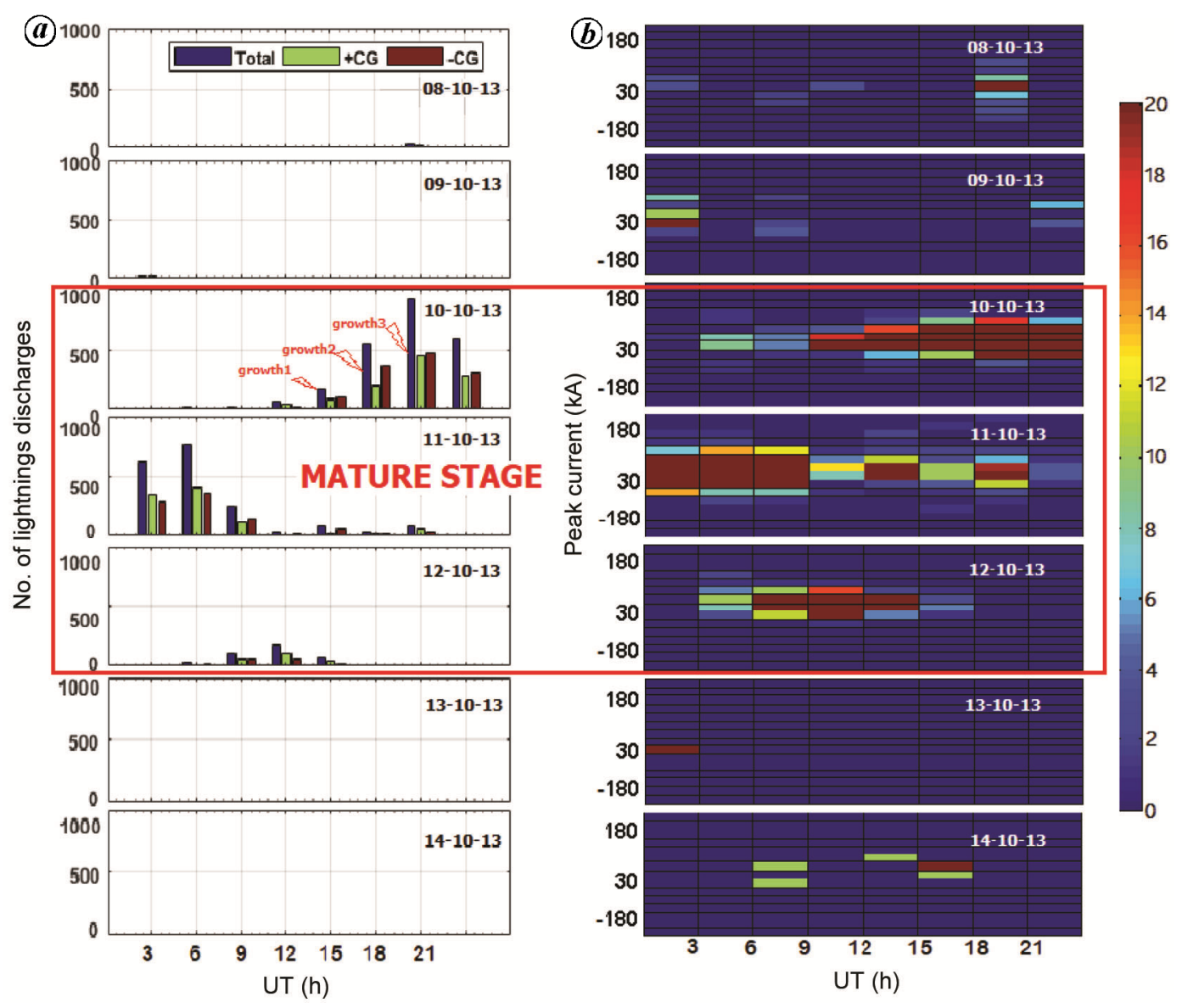

Figure 3. $\boldsymbol{a}$, Distribution of total lightning discharges along with number of $\pm \mathrm{CG}$ discharges in the eye of the cyclone during $8-14$ October 2013. $\boldsymbol{b}$, Peak current (kA) radiated by $\pm C G$ discharges.

stage of the cyclone. Such instances of $+\mathrm{CG}$ and $-\mathrm{CG}$ variations were also seen in earlier studies of lightning associated with cyclones ${ }^{9-11}$. The anomalous distribution of $+\mathrm{CG}$ and $-\mathrm{CG}$ presents their important role in the development of different stages of the storm, which demands for more such studies of tropical cyclone cases from the Bay of Bengal basin.

From the observations it is evident that during the rapid intensification stage of VSCS Phailin from 10 to 11 October, we observed maximum number of high-strength lightning discharges in the eye of the cyclone on the line of track. When the SCS intensified into a VSCS at around 06:00 h UT on 10 October, a steep rise in lightning activity followed which was marked as three bursts of stages 1-3 in Figure 3. On 11 October, maximum number of lightnings in the eye of the cyclone was observed during first half of that day when the cyclone attained the intensity of T6.0 with wind speed of $115 \mathrm{kn}$ (215 kmph). The maximum peak current radiated by a lightning in the eye of the cyclone on 11 October was observed to be $202 \mathrm{kA}$. After landfall of the storm during 11-12 October, an immediate and steep decline of lightning activity from the inner core eye of the storm was recorded. Hence we can see that energetics of lightning discharges in the eye of the cyclone very well correlates with cyclone intensification and dissipation, and hence can be used for the prediction of cyclone intensity.

To the best of knowledge, there have been no previous studies on the energetics of lightning discharges associated with a cyclone from the Indian region. We discuss our observations in light of reports in comparison with studies conducted in other open oceans such as Atlantic Ocean, Pacific Ocean, etc. from other countries and continents. Emanuel ${ }^{13}$ has stressed upon the increasing destructiveness of tropical cyclones over the past 30 years. The theoretical and modelling approach in the study stresses on the increasing power dissipation by tropical cyclones due to increasing sea surface temperature in the recent past. Hence the power dissipation in terms of lightning activity associated with a tropical cyclone is of importance for understanding the tropical cyclone energetics. The lightning activity results in drawing million volts of potential from clouds to the ground, and when this potential is supported by heat engine of the tropical cyclone, it can be more devastating to the increasing coastal population. In this study, the observed maximum peak current of lightning discharge is $202 \mathrm{kA}$, which is sufficiently high for a tropical cyclone to 
become more destructive as suggested in previous studies ${ }^{1,6,19,20}$. Lightning discharges from tropical storms with peak current having magnitude greater than $\sim 60 \mathrm{kA}$ are also reported to be potential generators of upper atmospheric perturbations ${ }^{9,27,28}$.

Some studies have reported lightning outbreaks prior to and during tropical cyclone intensity changes ${ }^{5,9-11}$. In this study, we found a steep increase in lightning discharge outbreaks around 18-21 UT hours on 10 October, prior to and during the change in intensity from T4.0 to T6.0. Such a study on the occurrence of lightning discharges in the eye of the cyclone prior to strengthening of the tropical cyclone can be a good tool for cyclone intensity forecasting. Also, charge separation in the convective clouds is important to understand electrical structure of a cyclone. Earlier studies ${ }^{22}$ on Hurricane Katrina from the Atlantic basin did not focus upon the development of charge separation in clouds that advance to develop bipolar structures inside a convection and then the discharge of the excess charge build-up in the convective clouds ${ }^{9,22}$. Hence we studied the charge separation and in the case of Phailin, we observed a spike in $-\mathrm{CG}$ and $+\mathrm{CG}$ outbreaks in the eye of the cyclone during the change in storm intensity from T4.0 to T6.0 on 10 October. Figure 3 shows gradual increase in $\pm \mathrm{CG}$ lightning activity in three significant steps. The $+\mathrm{CG}$ discharge was dominant on 11 October and -CG discharge was dominant during strengthening stages in the eye of the cyclone. We also observed that during the mature stage of the cyclone from 10 to 12 October, there was a close but not exact balance between $+\mathrm{CG}$ and $-\mathrm{CG}$ discharges. Out of the total discharges, +CG was $45.73 \%$ and $-\mathrm{CG}$ was $54.27 \%$ on 10 October. On 11 October, $+\mathrm{CG}$ was $51.73 \%$ and $-\mathrm{CG}$ was $48.27 \%$. For 12 October 2013, +CG was $57.78 \%$ and - $\mathrm{CG}$ was $42.22 \%$. Observations suggest that during intensification stages, $-\mathrm{CG}$ discharge was dominant and during dissipation stages $+\mathrm{CG}$ was dominant. Hence observations of electrical signatures such as details of peak current, location, occurrence time of lightning discharges in the eye of the cyclone imply that polarity distribution may be important for sustaining a bipolar structure of storm clouds and thereby help in intensification of the cyclone.

\section{Summary}

VSCS Phailin wreaked havoc on people living in the coastal areas. The associated adverse weather that accompanied Phailin such as thunderstorms, lightning discharges, heavy rainfall, gusty winds, strong gales and storm surges caused extreme damage to life and economy in the southern parts of Odisha and eastern parts of Andhra Pradesh ${ }^{25}$. According to reports, nearly one million coastal residents were relocated in a massive evacuation effort ahead of Phailin. Increasing number of cyclones with increasing global temperatures is also a major concern for the future. We studied the lightning discharge and its \pm polarity along with its radiated peak current from the eye of VSCS Phailin, which occurred in the Bay of Bengal during 8-14 October 2013. The strength and polarity of lightning discharges in the eye of the cyclone during each subsequent stage of development of the cyclone was analysed. The lightning activity in the eye of the cyclone showed maxima during the period of rapid intensification of the storm from 10 to 11 October 2013, prior to landfall. The observations show that lightning activity in the inner core of a tropical cyclone is maximum during storm intensification stages. Hence monitoring of lightning activity associated with tropical cyclones may be used along with other available earlywarning systems for tracking the development of intensity changes in the cyclone and thereby prediction of intensity of the cyclone and to reduce casualties and damage to property. In this, we analyse the electrical signature of the cyclone from the Indian region and further studies are required with more number of cyclone cases.

1. Matsuura, T. and Yumoto, M., Tropical Cyclones, Natural and human induced hazards, vol. II.

2. Dvorak, V. F., Tropical cyclone intensity analysis and forecasting from satellite imagery. Mon. Weather Rev., 1975; doi:https:// doi.org/10.1175/1520-0493(1975)103<0420:TCIAAF $>2.0$. CO;2.

3. Frank, W., The structure and energetics of tropical cyclone. Mon. Weather Rev., 1977, 105, 1119-1135.

4. Guinn, T. A. and Schubert, W. H., Hurricane spiral bands. J. Atmosp. Sci., 1993, 50, 3380-3403.

5. Wang, Y., How do outer spiral rainbands affect tropical cyclone structure and intensity? J. Atmosp. Sci., 2009; doi:https:// doi.org/10.1175/2008JAS2737.1.

6. Wang, Y. and $\mathrm{Xu}, \mathrm{J}$., Energy production, frictional dissipation, and maximum intensity of a numerically simulated tropical cyclone. J. Atmosp. Sci., 2010; doi:https://doi.org/10.1175/ 2009JAS3143.1.

7. Xu, J. and Wang, Y., Sensitivity of tropical cyclone inner core size and intensity to the radial distribution of surface entropy flux. J. Atmosp. Sci., 2010; doi:https://doi.org/10.1175/2010JAS3387.1.

8. Li, Q., Formation and quasi-periodic behavior of outer spiral rainbands in a numerically simulated tropical cyclone. J. Atmosp. Sci., 2012; doi:https://doi.org/10.1175/2011JAS3690.1.

9. Thomas, J. N., Solorzano, N. N., Cummer, S. A. and Holzworth, R. H., Polarity and energetics of inner core lightning in three intense North Atlantic hurricanes. J. Geophys. Res., 2010; doi:10.1029/2009JA014777.

10. Zhang, W., Zhang, Y., Zheng, D. and Zhou, X., Lightning distribution and eyewall outbreaks in tropical cyclones during landfall. Mon. Weather Rev., 2012; doi:10.1175/MWR-D-11-00347.1.

11. Zhang, W., Zhang, Y. and Zhou, X., Lightning activity and precipitation characteristics of Typhoon Molave (2009) around its landfall. Acta Meteorol. Sin, 2013; https://doi.org/10.1007/s13351013-0510-3.

12. Samsury, C. E. and Orville, R. E., Cloud-to-ground lightning in tropical cyclones: a study of hurricanes Hugo (1989) and Jerry (1989). Mon. Weather Rev., 1994; doi:10.1175/1520-0493.

13. Emanuel, K., Increasing destructiveness of tropical cyclones over the past 30 years. Nature, 2005; doi:10.1038/nature03906.

14. Kaplan, J., DeMaria, M. and Knaff, J. A., A revised tropical cyclone rapid intensification index for the Atlantic and eastern North 
Pacific basins. Weather Forecast., 2010; https://doi.org/10.1175/ 2009WAF2222280.1.

15. Cecil, D. J. and Zipser, E. J., Relationships between tropical cyclone intensity and satellite-based indicators of inner core convection: $85 \mathrm{GHz}$ ice scattering signature and lightning. Mon. Weather Rev., 1999, 127, 103-123.

16. Cecil, D. J., Bucehler, D. E. and Blakeslee, R. J., Gridded lightning climatology from TRMM-LIS and OTD: dataset description. Atmosp. Res., 2012, 135-136, 404-414.

17. Boccippio, D., Koshak, W. and Blakeslee, R., Performance assessment of the optical transient detector and lightning imaging sensor. Part I: predicted diurnal variability. J. Atmosp. Ocean. Technol., 2002; https://doi.org/10.1175/1520-0426(2002)019< 1318:PAOTOT>2.0.CO;2.

18. Nag, A., Murphy, M. J., Schulz, W. and Cummins, K. L., Lightning locating systems: insights on characteristics and validation techniques. Earth Space Sci., 2015; doi:10.1002/2014 EA000051.

19. Abarca, S. F., Corbosiero, K. L. and Vollaro, D., The world wide lightning location network and convective activity in tropical cyclones. Mon. Weather Rev., 2011; https://doi.org/10.1175/2010 MWR3383.1.

20. Price, C., Asfur, M. and Yair, Y., Maximum hurricane intensity preceded by increase in lightning frequency. Nature Geosci., 2009, 2, 329-332.

21. Demaria, M., Demaria, T. R., Knaff, J. and Molenar, D., Tropical cyclone lightning and rapid intensity change. Bull. Am. Meteorol. Soc., 2012; doi:10.1175/MWR-D-1100236.1.

22. Squires, K. and Businger, S., The morphology of eyewall lightning outbreaks in two category-5 hurricanes. Mon. Weather Rev., 2007, 136, 1706-1724.

23. Saffir, H. S., Hurricane wind and storm surge. Milit. Eng., 1973, 423, 4-5.

24. Simpson, R. H., The hurricane disaster potential scale. Weatherwise, 1974, 27(169), 169-186.
25. IMD, A report on very severe cyclonic storm PHAILIN. Cyclone Warning Division, India Meteorological Department, Ministry of Earth Sciences, Government of India, 2013.

26. Vagasky, C., Enveloped eye-wall lightning: the EEL signature in tropical cyclones. J. Operational Meteorol., 2017; https://doi.org/10.15191/nwajom.2017.0514.

27. Barrington-Leigh, C. P. and Inan, U. S., Elves triggered by positive and negative lightning discharges. Geophys. Res. Lett., 1999; doi:10.1029/1999GL9000059.

28. Cheng, Z., Cummer, S. A., Su, H.-T. and Hsu, R.-R., Broadband VLF measurement of Dregion ionospheric perturbations caused by lightning electromagnetic pulses. J. Geophys. Res., 2007; doi: 10.1029/2006JA011840.

ACKNOWLEDGEMENTS. We thank the Director, Indian Institute of Geomagnetism, Allahabad for encouragement and support. We also thank the Cyclone Warning Services (http://www.imd.gov.in/pages/ services_cyclone.php) of IMD for providing access to Phailin genesis and intensification data; Meteorological and Oceanographic Satellite Data Archival Centre, SAC, Indian Space Research Organisation, India (https://mosdac.gov.in/) for Kalpana-1 Infrared imagery data; and Morris Cohen and Vaisala Inc. (https://www.vaisala.com) for providing the GLD360 lightning data. A.K.M. thanks Science and Education Research Board, New Delhi for financial support under Ramanujan Fellowship (File No SB/S2/RJN-052/2016) and Faculty Recharge Programme (ID FRP62343) of the University Grant Commission, New Delhi.

Received 21 September 2018; revised accepted 11 October 2019

doi: $10.18520 / \mathrm{cs} / \mathrm{v} 118 / \mathrm{i} 3 / 421-427$ 